\title{
A Scientific Legacy: Theory of Dynamic Interactions
}

\author{
Veronica Barceló \\ Advanced Dynamics C.B., Madrid, Spain \\ Email: gestor@advanceddynamics.net
}

How to cite this paper: Barceló, V. (2017) A Scientific Legacy: Theory of Dynamic Interactions. World Journal of Mechanics, 7, 85-100.

https://doi.org/10.4236/wjm.2017.73009

Received: December 27, 2016

Accepted: March 24, 2017

Published: March 29, 2017

Copyright $\odot 2017$ by author and Scientific Research Publishing Inc. This work is licensed under the Creative Commons Attribution International License (CC BY 4.0).

http://creativecommons.org/licenses/by/4.0/

\begin{abstract}
This paper describes the theses that constitute the Theory of Dynamic Interactions. It is the scientific legacy of its promoter, Dr. Barceló who, after more than forty years developing this research project, has published his first book in the English language: New Paradigm in Physics. This book, as well as the bibliography and videos on this dynamic theory, is described in this article, which analyzes the behavior of rigid bodies subjected to accelerations by rotational movements, contributing new hypotheses of dynamic behavior.
\end{abstract}

\section{Keywords}

Paradigm, Non-Inertial Dynamics Systems, Intrinsic Rotation, Orbit, Dynamic Model

\section{Introduction}

The laws of Newton refer to systems in inertial references, that is, in a uniform motion or a steady state.

But in our universe, celestial bodies are in constant orbitation and rotation. Physics calls these movements non-inertial, and they are regulated by another dynamic. In systems which are non-inertial, Newton's Laws are not necessarily fulfilled.

Dr. Barceló has developed new dynamic hypotheses for accelerated systems. On the basis of certain dynamic assumptions, and with a new interpretation of the observed behavior of rotating bodies, Dr. Barceló has developed new dynamic hypotheses for accelerated systems. Which enable us to conclude that, it is possible to configure a new mathematical model, in the dynamic theory of rotating fields. Also, new laws of dynamic [1] behavior for non-inertial systems.

This new model would enable us to justify behavior that, until now, has been considered chaotic or has not been sufficiently understood. Its results have been 
verified by experiments and computer simulations.

The results obtained allow us a new perspective on the dynamics of the cosmos, unknown to date.

The author concludes that there is a scientific space, hitherto unstructured, in dynamics and specifically in the field of rigid bodies subjected to accelerations by multiple simultaneous non-coaxial rotations.

In NEW PARADIGM IN PHYSICS [2], the author describes the deductive process followed that led to the conception of the Theory of Dynamics Interactions (TDI). This theory puts forward new keys to explaining the dynamics of our environment and to better understand the universe. Moreover, it studies inertial forces and incorporates inertial reactions into the structure of a new, rotational dynamics of accelerated systems. The theory generalizes these dynamics concepts which had become de-structured in classical mechanics. Also, enables us to confirm and understand the physical and mathematical correlation that holds between orbiting and intrinsic rotation. But also, the dynamic equilibrium of our universe and, therefore, analyzing the behavior of those bodies with intrinsic rotation, to better understand the reason why we live in a world with nights and days, with sunsets and sunrises...

A team has been carrying out this physics research project for over 35 years, searching for nomological relations of non-inertial systems. As a result, they have found laws of dynamic behavior in environments where the laws of Classical Mechanics are not applicable.

One of their conclusions is that in the last two hundred and fifty years grosses mistakes has been accepted by the scientific community, preventing the true development of human knowledge in this area of nature.

Through repeated experimental tests they reliably saw how certain accepted mathematical formulations do not faithfully show the true dynamic behavior of bodies subject to accelerations by simultaneous non-coaxial rotations. In these studies founded that it is easily seen simultaneous intrinsic rotation and orbiting movements in nature, when until now there was no physical or mathematical model that established a scientific correlation between both movements. The author also had proposed the aporia that there could be a nomological physical-mathematical correlation between both movements: rotation and orbiting.

\section{Content}

For all this, and as a summary of the Advanced Dynamics team's long years of study and research, this new text, NEW PARADIGM IN PHYSICS, is published in which:

- The possible errors in classical rotational dynamics are identified.

- A diagnosis of these conceptual errors is deduced.

- The reasoning for the causes of these errors suggests alternative dynamic hypotheses.

- From these new hypotheses, a new General Theory of Dynamics is deduced, in which classical mechanics constitutes the specific structure of knowledge 
about inertial systems.

- It proposes a structure of dynamic knowledge that is broader and more general than the existing one, incorporating rotational dynamics as part of it.

- A theory of specific behavior is established for non-inertial systems.

- Axioms and laws of behavior are developed for non-inertial systems with axial symmetry.

- A specific mathematical model and an equation of motion for rotational dynamics are made.

- Experimental testing and verification of the mathematical model and its laws is performed.

- These experimental tests are recorded audio-visually, which permits their repetition and, if necessary, falsifiability.

- Using a computer, a simulation model is developed from this mathematical model.

NEW PARADIGM IN PHYSICS is a summary and presentation of all this process of knowledge management on dynamics, which is congruent and respectful of accepted theories, since it also includes and maintains classical mechanics as a specific part of this structure of human knowledge, however, limiting it to inertial dynamic systems. Simultaneously, also maintaining full coherence with Einstein's theories.

Dr. Barceló believes that these new dynamic models can be applied to the mechanics of both celestial systems in the same plane, and to Saturn's rings; to planetary systems and in general to celestial mechanics.

However, this algorithm also allows for many other scientific or technological applications [3], for example, for use in astronautics [4], in plasma confinement in fusion reactors [5] [6], or in predicting cyclones and hurricanes [7].

Having reviewed the science literature of the last two centuries, is not found similar analysis or study on rigid solid systems or bodies subject to external actions, that generate simultaneous accelerations that do not coincide in space. So, the work of Dr. Barceló is original, and the conclusions that he proposes have not been dictated until now.

However, although the error detected was identified and a new physical theory was developed, there are still ample areas of knowledge development in this new dynamics of accelerated systems for the author.

The author initially carried out a Previous Study, with the compilation of existing studies in rotational dynamics, or related to it, to get to know the historical evolution of this body of scientific thought.

Below, we describe the contents of the book: NEW PARADIGM IN PHYSICS, making a brief summary of volume I of this treatise.

In the first chapter: 0 . Forgotten physics ${ }^{1}$, the author raises his initial doubts and the dynamic conjectures that his teacher, Miguel Catalán aroused, about a niche of knowledge that, in his opinion, had not evolved since the nineteenth

${ }^{1}$ The author considers that the first numerical digit of our decimal system is zero, not one. Therefore, he structures its numbering starting with the digit zero. 
century. The author expresses his nonconformity regarding the acceptance of admitted rotational dynamics, because he had serious rational doubts about it.

In the second chapter: 1 . The Theory of Relativity, Dr. Barceló confirms its consistency with the theories of Einstein, initiating the chapter with this paragraph: Our thinking is based on the Einstein's Theory of Relativity in both of its versions. Special Relativity which can be applied to all physical phenomena, except for gravity, and General Relativity which can be applied to gravity and its relationship with other forces of nature [8].

In this chapter, the concept of rotation as conceived by Einstein is analyzed, confirming that there is no contradiction with the dynamic theory that it proposes. Nevertheless, it is recognized that the Theory of Relativity is born of dynamic translational thinking and it is later on when rotational concepts are added, so a possible revision of this rotational development is suggested. This is a question that will be reiterated by the author in the second volume of his treatise.

On developing his theory, Einstein obtained a surprising result, the curvature of space-time: Einstein's point of view is that locally, energy determines the curvature of space-time, and determines the motion of bodies [9]. In effect, he comes to the conclusion that the mere presence of a mass, deforms space-time around it, and therefore, affects the behavior of any mobile object (See Figure 1). As a corollary, it may be argued that gravity is not a force in itself, but a consequence of the deformation of space-time. The analogy that is usually used to better understand these conclusions, first proposed by Edington, is that of a tensile and elastic surface on which a heavy object is placed. The object will sink, bending and stretching that surface [10].

Nevertheless, in the history of science, when the orbiting movement of the Earth, that of the Moon or of any other planet has been analyzed, the analogy of the stone thrown with a sling has been proposed. Galileo, Newton and Einstein have used this unfortunate analogy, since in the author's opinion, the stone ejected by the sling does not necessarily spin, while celestial bodies rotate intrinsically as they orbit. This is one of the indications that provoked the dissatisfaction of our author.

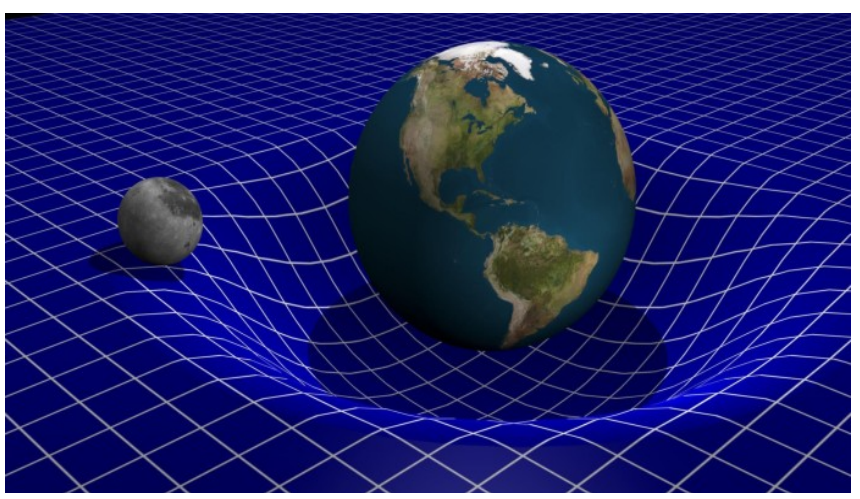

Figure 1. Representation of space-time according to the General Theory of Relativity. Apparent gravitational attraction is nothing more than the result of the deformation of space-time due to the masses of the Sun and Earth. 
In the third chapter: 2. Classical mechanics, the author reminds us of the concepts and principles of classical mechanics needed for the development of his research project, and those which he believes may be of interest to the reader. Notwithstanding, this analysis was dealt with in greater detail in two books previously published by the author. The Flight of the Boomerang, (2006) and A Rotating World, (2008).

In this chapter, it is remembered how Einstein identified the force of gravity as a fictitious force, which up to this date has been ratified, because the alleged graviton has not been detected, which where appropriate would have given it its own nature as a real force.

In the fourth chapter: 3. Experimental tests, we describe the experimental tests, which were initially carried out successfully, in order to test the new dynamic hypotheses that had been conceived. Experimental tests were also done with simple pendulums holding a gyroscope, (see Figure 2) [11]. In addition to the singular precession movement proper to the gyroscope, an unexpected action occurred, given that the rotating pendulum stopped swinging on a plane, with the gyroscope following a path the projection of which on the floor could be an ellipse or a circle. This reaction disappeared if the gyroscope stopped rotating, thus causing in this case an apparently plane swinging of the pendulum, as per usual [12].

With the demonstration of the experimental tests carried out, both by the research team of Advanced Dynamics and by third parties, the initial dynamic hypotheses were confirmed.

In the fifth chapter: 4 . Reinterpretation of the behavior of bodies, a conceptual generalization is proposed that bodies in space are endowed with angular momentum and subjected to multiple excitations of rotation.

The author proposes that rotational inertia is an inherent property of mass. It

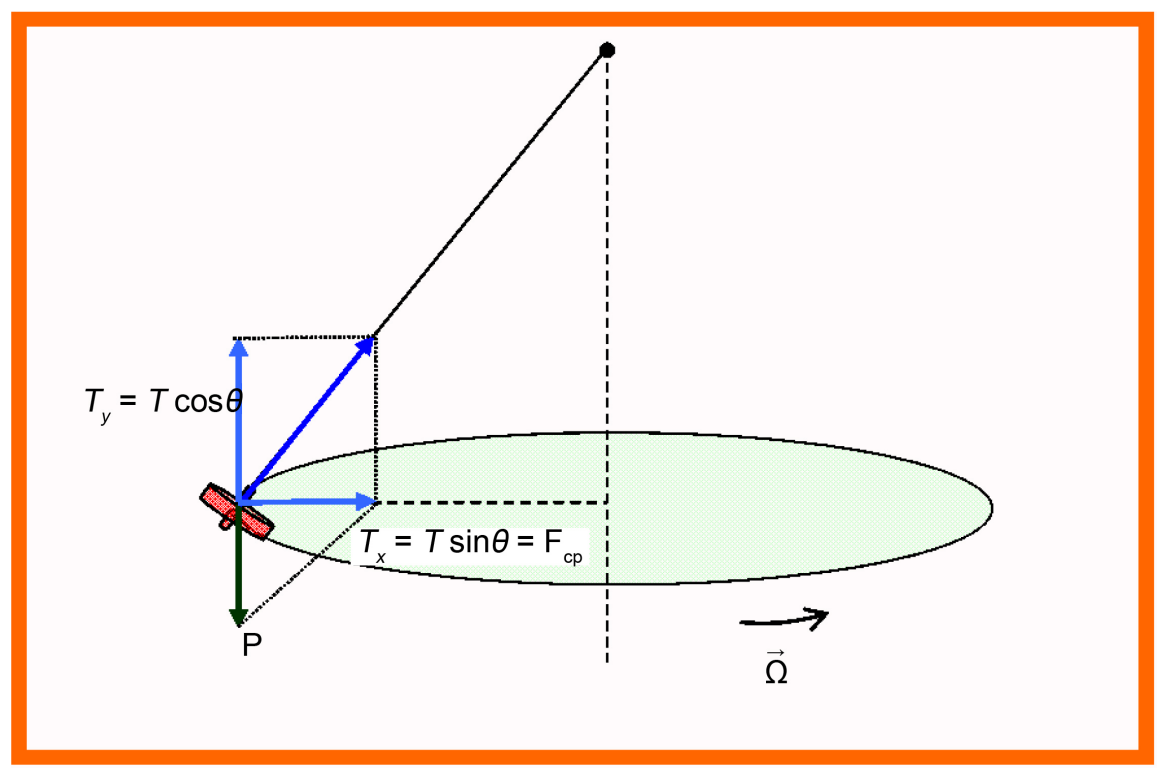

Figure 2. Barceló's gyroscopic conical pendulum, with spatial movement [11]. 
is an attribute that is kept constant and determines, when there is an intrinsic rotation movement, its impossible vectorial composition with other rotational movements. New concepts in rotational dynamics of non-inertial systems are analyzed, establishing the bases of a new dynamic theory.

In the last chapter: 5. General Theory of Mechanics, the mathematical formulation of the theory is proposed, as is a qualitative model for storing and structuring mechanical knowledge about rigid solids. The author suggests a new theory, which serves as a framework for all types of mechanical knowledge about rigid solids, which is organized and structured according to a unified criterion, for a better global understanding, avoiding the incorporation of fictitious or non-real concepts to describe the observed manifestations. Or preventing the unstructured incorporation of apparently anomalous phenomena, as has been illogically done in classical mechanics, this being the case of fictitious forces or gyroscopic phenomena.

It is precisely what is reiterated by the author, that this is the main object of the work and of this chapter, specifically, to try to establish a NEW PARADIGM IN PHYSICS.

It proposes new rotational and dynamic concepts, establishing the axioms of this general theory, suggesting the development of a new logical and pyramidal structure of dynamics, differentiating between:

- Dynamics of inertial systems

- Dynamics of accelerated or non-inertial systems

Non-inertial system dynamics would cover Newtonian dynamics and all the dynamics formulations of classical mechanics and would be fully valid for moving objects with uniform velocity. It is a consecrated dynamics that does not need to be complemented to today, although its revision is suggested in cases where it has been inappropriately applied to non-inertial systems.

In the case of accelerated mobile objects, the author suggests developing a Dynamics of non-inertial systems, proposing for this purpose, to conceive a General Theory of Dynamic Interactions (GTDI).

Finally, and within this same discipline, he also proposes a Theory of Dynamic Interactions (TDI), as a new paradigm for dynamic systems with non-inertial axial symmetry, because Dr. Barceló considers that this theory enables a better explanation and a more accurate prediction of mobile behavior in such accelerated cases. The theory deduces a general equation of motion for bodies endowed with angular momentum, when subjected to successive non-coaxial pairs. It is the general equation of motion of non-inertial systems with axial symmetry. In this equation the rotation operator $\overrightarrow{\vec{\Psi}}$ is a matrix that transforms the initial velocity $\vec{V}_{0}$, by means of rotation, into the velocity that corresponds to the each one of the successive dynamic states $\vec{v}$.

$$
\vec{v}=\vec{\Psi} \vec{V}_{0}
$$

Since the rotational operator $\overrightarrow{\vec{\Psi}}$ is function of $\Omega t$, which clearly indicates the relationship between the angular velocity $\Omega$ of the orbit, the initial angular velocity of the body $\omega$, and its translation velocity $\vec{v}$. 
In Volume II, its publication announced for 2018, the author plans to develop different cases for the application of the Theory of Dynamic Interactions (TDI), its laws of behavior and possible new scientific and technological applications. For example, dynamic confinement in nuclear fusion reactors for the generation of clean electric energy, or the dynamic treatment of typhoon and hurricane behavior. Also, the conceptual justification of specific examples, such as the boomerang or the gyroscopic pendulum, a scientific instrument conceived by Dr. Barceló, which faithfully demonstrates the theory. In this volume, we will also see dynamic assumptions, which are currently confusing, such as in the case of the Pioneer space probes' so-called dynamic anomalies, (Volume II, Chapter 9).

Also in Volume II and Chapter 7, through TID, the author will justify other phenomena confirmed by observation, but which cannot be solved by Newton's laws or cannot be predicted in classical mechanics.

In Chapter 13, the author will propose a new analysis of relativistic rotations, suggesting comments and qualifications to the theory of relativity, which should be taken into account when asserting the existence of rotational relativistic dynamics for non-inertial systems.

\section{The Contented Man}

The front page of New paradigm in physics (see Figure 3) incorporates a self-portrait made by the author at eleven years of age, and that a few years later appeared in North American magazines (see Figure 4) and newspapers (see Figure 5).

On the back page of the book, the latter is justified in this way, while dedicating the book to the memory of his teacher Miguel A. Catalán:

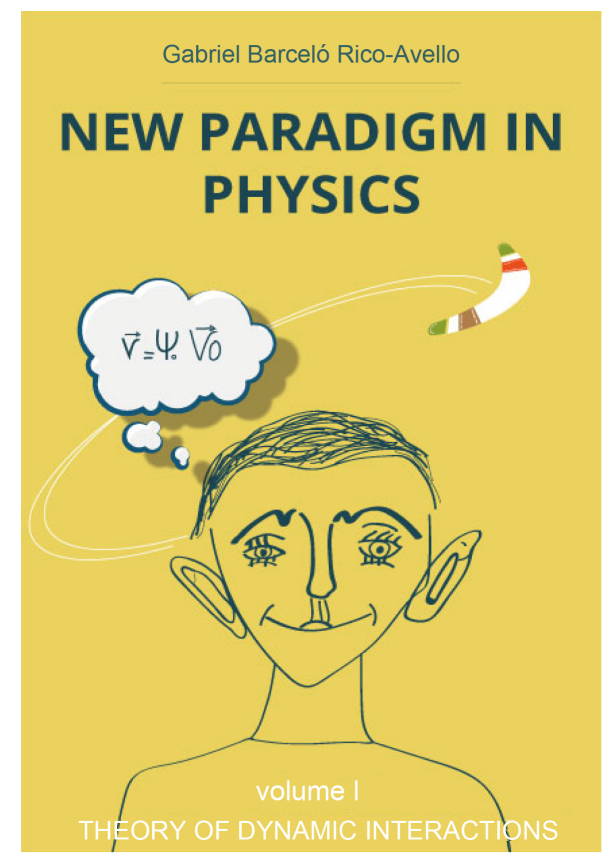

Figure 3. Front page of New paradigm in physics with a self-portrait of the author. 


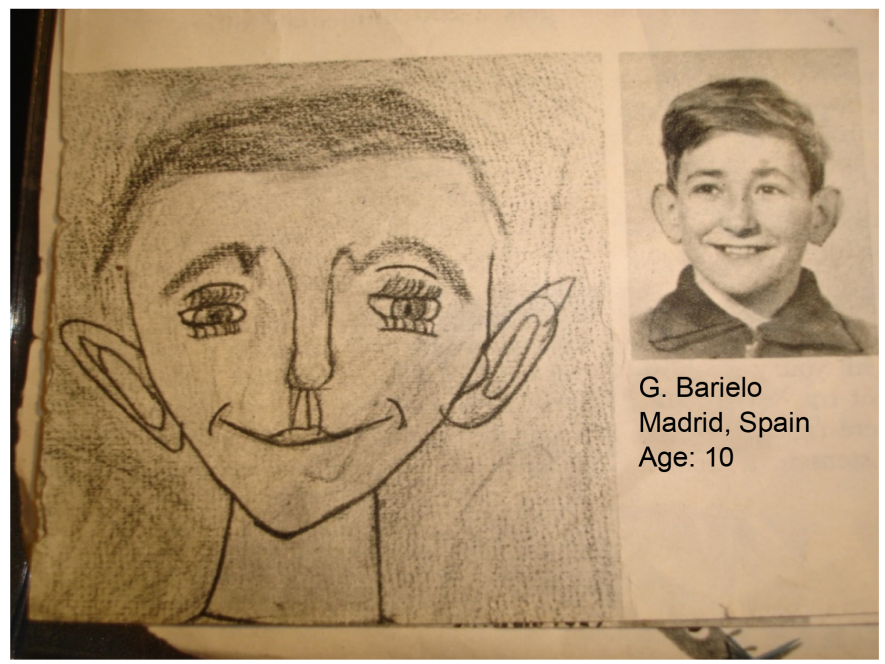

Figure 4. A cutting from the Reader's Digest sent by Miguel Catalán, from Princeton University's Palmer Physical Laboratory (New Jersey) in 1953.

\section{In memory of our teacher Miguel A. Catalán Sañudo.}

The drawing on the front page is a self-portrait by the author when he was 11 years old. It was published in several newspapers and American magazines in 1953. Miguel A. Catalán sent it by post to the author, with newspaper cuttings informing him of the news item [13].

The author himself describes this personal anecdote in this way: I went to the school, the same as every morning, one day in late March, 1953. I joined the class, but unexpectedly, I was called away urgently by the head $s$ office. In those years, I was a rather mediocre student, completely unconcerned about qualifications, so any mention or individual notice, used to pose some reprimand or punishment, which was always clearly unjustified.

So, as I went diligently to that office, I would recompose in my head the reasons for the possible packages I might receive, without really understanding the urgency of the call. When I arrived at the head s office, with great astonishment on my part, I was greeted with laughter and jokes by some teachers. That was incomprehensible! I did not understand anything that was happening, and they handed me an envelope from the United States, addressed to me. I barely understood what was happening, I thought it was a misunderstanding, and that it was a letter to my father, who was called the same as me. But they said no, that was for me, a student of the school, and that it was sent by Miguel Catalán, the husband of the Headmistress... Well I still did not understand anything at al! I was urged to open the letter quickly. As I opened the envelope, trying to stammer out something, there were clippings of American newspapers in which my photo appeared, and the reproduction of a sort of caricature-self-portrait that three years ago I had done in a drawing class at school. American newspapers identified me with the heading. "The contented man." In addition, there was also a letter from the same Mr. Catalán addressed to me.

I did not understand anything, I appeared in a photo in a magazine and in an 


\section{INTERNATIONAL EDITION}

THE NEW YORK TIMES, MONDAY, MARCH 16, 1953.

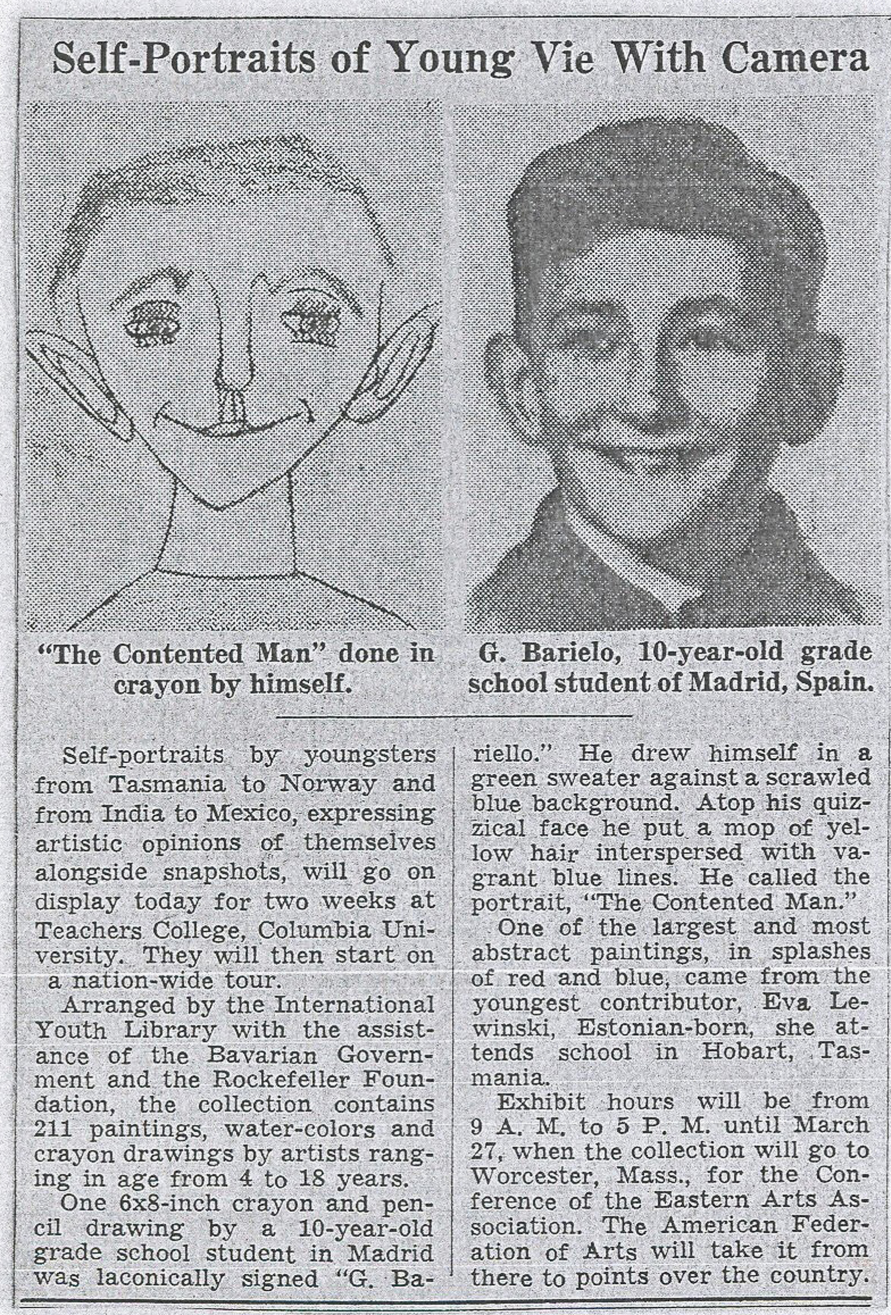

Figure 5. Newspaper cutting sent to Gabriel Barceló by Miguel Catalan in 1953 [14].

American newspaper. The teachers tried to translate the texts that accompanied those photos, not without some difficulty. Then I began to understand what it was about. Three years earlier, in drawing class, we had each been given a mirror and told to do a self-portrait. I remembered, because some of my school mates at that time did not know what a self-portrait was, and the teacher had to explain it. The school had sent a series of these drawings to a competition at an American organization. These drawings, along with those of other European children, had been a traveling exhibit throughout Europe funded by the Rockefeller Foundation, and which, in the end, had been exhibited at Columbia University in New York, being mine, apparently one of the most original, at least so the art critics 
of those newspapers believed.

My initial concern, and subsequent bewilderment, was now a source of joy to all. Little by little I understood what had happened, filling me with satisfaction that our teacher Miguel Catalán had identified me from his laboratory in the USA, that he would have written to me sending me the newspaper clippings with my review and that he would treat me as a good friend! All of this without hardly knowing him. But also, I was flattered that the Americans had noticed my drawing, and that they treated me as a "man", that is to say a man as I understood it, and besides, according to them, content.

I remembered again that day in drawing class. I had kept me well entertained that self-portrait, and the class rushed by, so that when it was time to finish, it seemed to me that I had not been able to finish my drawing. My mother drew and painted very well, so when I checked the work, before giving it in, I had wanted to tear it up. It seemed to me that it was unfinished and that, unfortunately, it was very bad at drawing. When he saw that self-portrait again, a drawing of a caricature, no matter how much the Americans had noticed him, I did not understand what merit it could have: The person who painted well was my mother, she did know how to draw! [15]

\section{Conclusions}

With NEW PARADIGM IN PHYSICS, Dr. Barceló intends to contribute his personal legacy to the development of dynamics, making his research known in a structured way, reporting the surprising results obtained in his research, and attracting interest in this area of knowledge, on rotational dynamics, and its many and notable scientific and technological applications.

This work is unpublished, and the conclusions proposed therein have not been stated to date by other authors.

Visit the following web sites for complete information on the Theory of dynamics Interactions: http://www.advanceddynamics.net/;

http://www.dinamicafundacion.com/

\section{References}

[1] Barceló, G. (2013) Theory of Dynamic Interactions: Laws of Motion. World Journal of Mechanics, 3, 328-338. https://doi.org/10.4236/wjm.2013.39036

[2] Barceló, G. (2017) New Paradigm in Physics, Vol. I: Theory of Dynamic Interactions. Amazon.

[3] Barceló, G. (2013) Technological Applications of the New Theory of Dynamic Interactions. Global Journal of Research in Engineering. Mechanical and Mechanics Engineering- $G$, 13, 33-39.

https://globaljournals.org/GJRE_Volume13/E-Journal_GJRE_(G)_Vol_13_Issue_5. pdf

[4] Martín Gutiérrez, A. (May 2015) Flight Simulator, Trip to Saturn. E.T.S.I. Aeronáuticos (U.P. Madrid). Degree Project.

[5] Barceló, G. Dynamic Interaction: A New Concept of Confinement. Global Journal of Science Frontier Research: A Physics \& Space Science, 16, 1-9. 
https://globaljournals.org/GJSFR_Volume16/E-Journal_GJSFR_(A)_Vol_16_Issue_ 3.pdf

[6] Barceló, G. (2014) Dynamic Interaction Confinement. World Journal of Nuclear Science and Technology, 4, 249-260. https://doi.org/10.4236/wjnst.2014.44031

http://www.scirp.org/journal/PaperInformation.aspx?paperID=51026\&

[7] Barceló, G. (2014) Dynamic Interactions in the Atmosphere. Atmospheric and Climate Sciences, 4, 828-840. https://doi.org/10.4236/acs.2014.45073 http://www.scirp.org/Journal/PaperInformation.aspx?PaperID=51584\#.VHB4YTSG To

[8] Barceló, G. (2017) New Paradigm in Physics, Vol. I: Theory of Dynamics Interactions. Chap. 1, The Theory of Relativity. Amazon.

[9] Jammer, M. (1976) In: Smarted, J.J.C., Ed., Problems of Space and Time, Macmillan Publishing Co. Inc., 27.

[10] Barceló, G. (2013) Imago Universi: A Story of the Human Conception of the Cosmos. Arpegio, Barcelona. http://www.editorialarpegio.com/

http://advanceddynamics.net/imago-universi/

[11] Cano, J. (2015) The Pendulum of Dynamic Interactions. Journal of Applied Mathematics and Physics, 3, 1186-1198. http://www.scirp.org/journal/jamp

[12] Barceló, G. (2017) New Paradigm in Physics, Vol. I: Theory of Dynamic Interactions. 3. Experimental tests, Amazon.

[13] Barceló, G. (2017) New Paradigm in Physics, Vol. I: Theory of Dynamic Interactions. Front Page Interior. Amazon.

[14] Barceló, G. (2012) Miguel A. Catalán Sañudo. Memoria Viva. Arpegio, Barcelona.

[15] Barceló, G. (2009) Mr. Catalán, Teacher at Colegio “Estudio”. ADANAE, Madrid. 


\section{Appendix A}

\section{Bibliography and References to TDI}

Included in this text are books, articles and references that may be consulted in connection with the Theory of Dynamic Interactions:

Álvarez Martínez, Alejandro \& Martín Gutiérrez, Almudena: "The Dance of the Spinning Top", Global Journal of Science Frontier Research: A physics \& space science. GJSFR A Volume 16 Issue 3, 2016.

https://globaljournals.org/GJSFR_Volume16/E-Journal_GJSFR_(A)_Vol_16_I ssue_3.pdf

Barceló, Gabriel: New Paradigm in Physics, Volume I: Theory of Dynamic Interactions. Amazon, 2017.

Barceló, Gabriel: A unique research project. Rotational dynamics of accelerated systems. November 2016. Journal of Madrid:

http://jsanchezmingo.blogspot.com.es/2016_11_01_archive.html

Barceló, Gabriel: Dynamic Interaction: A New Concept of Confinement", Global Journal of Science Frontier Research: A physics \& space science. GJSFR A Volume 16 Issue 3, 2016.

https://globaljournals.org/GJSFR_Volume16/E-Journal_GJSFR_(A)_Vol_16_I $\underline{\text { ssue_3.pdf }}$

Barceló, G.: "Theory of Dynamic Interactions: The Flight of the Boomerang II", Journal of Applied Mathematics and Physics, 2015, 3, Pages 545-555. Published On-line May 2015 in SciRes. http://www.scirp.org/journal/jamp

DOI: $\underline{10.4236 / j a m p .2015 .35067 .}$.

Barceló, G.: Theory of Dynamic Interactions: The Flight of the Boomerang", Journal of Applied Mathematics and Physics, 2, 569-580, Published On-line June 2014 Volume 2, Number 7: http://dx.doi.org/10.4236/jamp.2014.27063

http://www.scirp.org/journal/jamp

Barceló, G.: "Dynamic Interaction Confinement", World Journal of Nuclear Science and Technology Vol. 4 No. 4, October 29, 2014.

DOI: 10.4236/wjnst.2014.44031

http://www.scirp.org/journal/PaperInformation.aspx?paperID=51026\&

http://dx.doi.org/10.4236/wjnst.2014.44031

Barceló, G.: "On Motion, its Relativity and the Equivalence Principle", Journal of Modern Physics. Vol. 5, No.17, November 14, 2014.

DOI: $10.4236 /$ jmp.2014.517180

http://www.scirp.org/Journal/PaperInformation.aspx?PaperID=51422\#.VHB0 zzSG_To

http://dx.doi.org/10.4236/jmp.2014.517180

Barceló, G.: "Dynamic Interactions in the Atmosphere", Atmospheric and Climate Sciences. Vol. 4 No.5, November 20, 2014.

DOI: $10.4236 /$ acs.2014.45073.

http://www.scirp.org/Journal/PaperInformation.aspx?PaperID=51584\#.VHB4 YTSG_To 
http://dx.doi.org/10.4236/acs.2014.45073

Barceló, G.: "Technological Applications of the New Theory of Dynamic Interactions", Global Journal of Research in Engineering. Mechanical and Mechanics Engineering- $G$, Volume 13, Issue 5, 2013.

https://globaljournals.org/GJRE_Volume13/E-Journal_GJRE_(G)_Vol_13_Iss ue_5.pdf

Barceló, G.: Theory of Dynamic Interactions: Laws of Motion", World Journal of Mechanics, 3, 328-338. (2013) http://dx.doi.org/10.4236/wjm.2013.39036

Barceló, G.: "Proposal of New Criteria for Celestial Mechanics", International Journal of Astronomy and Astrophysics, 3, 2013, pp. 385-391. 2013.

http://dx.doi/org/10.4236/ijaa.2013.34044

Barceló, G.: Miguel Catalán and the history of the human conception of the cosmos. Text for a conference given on the occasion of the presentation of the book: Imago Universi. Editorial Arpegio, Madrid, May 30, 2013.

Barceló, G.: Imago Universi: A Story of the Human Conception of the Cosmos. Publisher: Arpegio: Barcelona, 2013.

http://www.editorialarpegio.com/

http://advanceddynamics.net/imago-universi/

Barceló, G.: "Analysis of Dynamic Fields in Non-inertial Systems", World Journal of Mechanics, Vol. 2, No. 3, 2012, pp. 175-180.

http://dx.doi.org/10.4236/wjm.2012.23021

Barceló, G.: Theory of Dynamic Interactions.El libre pensador, 2012.

http://www.ellibrepensador.com/2012/07/06/teoria-de-interacciones-dinamic

as-por-gabriel-barcelo/

Barceló, G.: The biographical trajectory of Miguel Catalán and his necessary claim. Text for a conference given at the "Leonardo Torres Quevedo" Center of Physical Technologies, Madrid. January 31, 2012.

Barceló, G.: Miguel A. Catalán Sañudo. Living Memory. Publisher: Arpegio: Barcelona, 2012.

Barceló, G.: The management of knowledge in the discovery of a new scientific method. Text for a conference given on the occasion of the XI Science Week. Faculty of Physical Sciences at Universidad Complutense de Madrid, November 16, 2011.

Barceló, G.: Analysis of Dynamics Field Systems Accelerated by Rotation. Dynamics of non-inertial systems. DeMSET-2011 Congress, Miami. USA.

http://www.coiim.es/forocientifico/FORO\%20CIENTFICO/Documentos/De MSET_2011_GBarcelo.pdf

Barceló, G.: On the Equivalence Principle AC-10-A.2.1.1. 61st International Astronautical Congress, Prague, CZ. Copyright (0 2010 by Advanced Dynamics. Published by the American Institute of Aeronautics and Astronautics, Inc.

http://www.coiim.es/forocientifico/FORO\%20CIENTFICO/Documentos/ON _THE_EQUIVALENCE_PRINCIPLE.pdf

Barceló, G.: Miguel A. Catalán and his enthralling life. Text for a conference given on the occasion of the X Science Week at the "Miguel Antonio Catalán" 
Center of Physics, CSIC. Madrid, 17 November 2010.

Barceló, G.: Dynamics of non-inertial systems. XXXII Biennial Meeting of the Spanish Royal Society of Physics. Ciudad Real, September 2009.

http://www.advanceddynamics.net/

Barceló, G.: Mr. Catalán.ADANAE. Madrid, 2009.

Barceló, G.: A Rotating World. Publisher: Marcombo: Barcelona, 2008.

http://www.dinamicafundacion.com/

Barceló, G.: Scientific restlessness. a step forward in the progress of society.

$\mathrm{Madr}+\mathrm{i}$

http://www.madrimasd.org/informacionidi/noticias/noticia.asp?id=37310\&tip $\mathrm{o}=\mathrm{g}, 2008$.

And in the gazette navarrainnova of the Navarre Innovation Agency $04 / 12 / 2008$

Barceló, G.: The Flight of the Boomerang. Publisher: Marcombo: Barcelona, 2006.

http://www.dinamicafundacion.com/

Barceló, G.: A New Rotational Dynamics of Interactions for the Planet Saturn. (Una nueva Dinámica Rotacional de Interacciones para el planeta Saturno), 2006.

http://dinamicafundacion.com/wp-content/uploads/2014/02/UNA-NUEVADINAMICA-ROTACIONAL-DE-INTERACCIONES-PARA-EL-PLANETA-SA TURNO.pdf

Barceló, G.: Anomalies of the Pioneer Space Probes, (Pioneer Anomaly). (Anomalías dinámicas en las sondas Pioneer), RSEF's 2005 biennial, the summary of which was published in the biennial's Summary Book,

http://dinamicafundacion.com/wp-content/uploads/2014/02/ANOMAL\%C3

\%8DAS-DIN\%C3\%81MICAS-EN-LAS-SONDAS-PIONEER1.pdf

http://www.solociencia.com/fisica/teoria-interacciones-dinamicas-justificacio $\underline{\text { n.htm }}$

Barceló, G.: The Theory of Dynamic Interactions. 2005.

http://www.solociencia.com/fisica/teoria-interacciones-dinamicas-teoria-inter acciones.htm

Bustamante, Santiago: Episode 183: The Flight of the Boomerang (The Theory of Dynamic Interactions) Saturday, June 13, 2015 Fallo de sistema Radio 3.

http://blog.rtve.es/fallodesistema/2015/06/puede-el-vuelo-del-bumer\%C3\%A1 n-ocultar-claves-muy-importantes-para-entender-la-din\%C3\%A1mica-de-nuest ro-entorno-y-comprender-el-un.html?cid=6a014e6089cbd5970c01bb0842db3a9

70d\#comment-6a014e6089cbd5970c01bb0842db3a970d

Cano, J.: “The Pendulum of Dynamic Interactions", Journal of Applied Mathematics and Physics, Vol.3 No.9, September 2015, 1186-1198. Published Online:

DOI: $10.4236 /$ jamp.2015.39146.

http://www.scirp.org/journal/jamp

Gómez, F.: Theory of Dynamic Interactions. Didactic essays in science and the 
humanities, 2008. http://www.unirioja.es/ensaya/conv_encurso.html

Martín Gutiérrez, Almudena. Dynamics of flat celestial systems and space probes. Archimedes Competition, Research Project. Madrid, 2016.

Martín Gutiérrez, Almudena. Flight Simulator, Trip to Saturn. (Simulador de vuelo, viaje a Saturno). E.T.S.I. Aeronáuticos (U.P. Madrid). Degree project. May, 2015.

Pérez, L. A.: "New Evidence on Rotational Dynamics", World Journal of Mechanics, Vol. 3, No. 3, 2013, Pages 174-177, doi: 10.4236/wjm.2013.33016.

http://www.scirp.org/journal/wjm http://dx.doi.org/10.4236/wjm.2013.33016

Ramos, A. M: An emerging inverse problem in the study of movements with non-coaxial intrinsic rotations of a disk. XX Conference on Differential Equations and Applications and X Conference of Applied Mathematics. Seville, September 2007. Presentation of the paper of the same name, the authors of which are: J. I. Díaz and A. M. Ramos and G. Barceló. Dept. of Applied Mathematics, Faculty of Mathematics, Universidad Complutense de Madrid,

http://www.advanceddynamics.net/

Report: New keys to understanding the dynamics of the universe. 2014.

http://www.pandora-magazine.com/cienciaytecnologia/nuevas-claves-para-en tender-la-dinamica-del-universo/

Research Blog: Extensive Report on the Investigations of Gabriel Barceló. March, 2016. Global Journal of Research in Engineering. The report incorporates the new scientific and technological advances achieved with the Theory of Dynamic Interactions.

http://blog.gjre.org/2016/03/behaviour-of-rotational-bodies.html

TESLA journal, No. 10 Summer 2016. Official Journal of the Madrid Industrial Engineers' Association (COAIN). Gabriel Barceló interview.

http://portal.coiim.es/uploads/files/b3cacc732a5f692f7e0a8844aa8a823b32f3d6 $\underline{003 . p d f}$

TESLA journal, $\mathrm{N}^{\circ} 10$, summer 2016. Official Journal of the Madrid Industrial Engineers' Association and COIIM, (COAIN). Report.

http://portal.coiim.es/uploads/files/b3cacc732a5f692f7e0a8844a $8 \mathrm{a} 823 \mathrm{~b} 32 \mathrm{f} 3 \mathrm{~d} 6$ 003.pdf

The texts presented to congresses or conferences are not included in this account.

\section{Appendix B}

\section{Experimental Tests and Videos}

Several test experiments have been conducted over recent years, the results of which have been fully satisfactory. These tests serve to confirm the dynamic hypotheses that underpin the Theory of Dynamic Interactions. Videos have been recorded of these tests that can be seen at the following links:

Theory of Dynamic Interactions_1

http://www.youtube.com/watch?v=P9hGgoL5ZGk\&feature=related 
Theory of Dynamic Interactions_2

http://www.youtube.com/watch?v=XzTrGEtJGXU\&feature=related

Theory of Dynamic Interactions_3.avi

http://www.youtube.com/watch?v=dtMqGSU9gV4\&feature=related

Theory of Dynamic Interactions_4.avi

http://www.youtube.com/watch?v=qK5mW2j2nzU\&feature=related

Barceló, G.: Theory of Dynamic Interactions.Videos, 2002.

http://www.youtube.com/watch?v=P9hGgoL5ZGk\&list=PL3E50CF6AEBEED $\underline{47 \mathrm{~B}}$

http://www.youtube.com/watch?v=XzTrGEtJGXU\&list=PL3E50CF6AEBEED $\underline{47 \mathrm{~B}}$

http://www.youtube.com/watch?v=XzTrGEtJGXU\&list=PL3E50CF6AEBEED $\underline{47 \mathrm{~B}}$

http://www.youtube.com/watch?v=dtMqGSU9gV4\&list=PL3E50CF6AEBEED 47B

http://www.youtube.com/watch?v=qK5mW2j2nzU\&list=PL3E50CF6AEBEE

$\underline{\mathrm{D} 47 \mathrm{~B}}$

http://www.youtube.com/watch?v=vSUkd4slHGQ

http://www.youtube.com/watch?v=P9hGgoL5ZGk\&feature=c4-overview-vl\&l ist=PL3E50CF6AEBEED47B

Bauluz, E.: New Dynamic Hypotheses. Madrid, 2011. This video showed the experiments carried out by Advanced Dynamics $S$. A. to prove and justify the http://www.youtube.com/watch?v=vSUkd4slHGQ\&feature=c4-overview\&list $=\mathrm{UUgDHgaGi} 2 \mathrm{I} 2 \mathrm{rmZNoanNbVWQ}$

http://www.youtube.com/watch?v=vSUkd4slHGQ

Sánchez Boyer, J.: Imago Universi. Video, Madrid, 2013.

https://vimeo.com/62247544

Pérez, L. A.: Reflecting New Evidence on Rotational Dynamics, 2013. Video. http://vimeo.com/68763196

Sanchez Boyer, J.: The Flight of the Boomerang II, Video. 2015.

https://www.dropbox.com/s/stng5b2co1441hk/Boomerang_ENG_mini.mp4?d $\underline{\mathrm{l}=0}$

https://www.youtube.com/watch?v=mGfrGW5fhOg\&feature=youtu.be https://vimeo.com/129383447

Pérez, L. A. The Pendulum of Dynamic Interactions.Video. 2015.

www.advanceddynamics.net/the-pendulum-video. https://www.dropbox.com/s/rrjb1786ub75a8h/PIDing_m.mp4?dl=0

Pérez, L. A.: The Dance of the Spinning Top.Video, Valladolid, 2015. www.advanceddynamics.net/spinning-top-video/ 
Submit or recommend next manuscript to SCIRP and we will provide best service for you:

Accepting pre-submission inquiries through Email, Facebook, LinkedIn, Twitter, etc. A wide selection of journals (inclusive of 9 subjects, more than 200 journals)

Providing 24-hour high-quality service

User-friendly online submission system

Fair and swift peer-review system

Efficient typesetting and proofreading procedure

Display of the result of downloads and visits, as well as the number of cited articles Maximum dissemination of your research work

Submit your manuscript at: http://papersubmission.scirp.org/

Or contact wjm@scirp.org 